\title{
On A Hybrid Approach for Treating Multi-Criteria Decision Making Problems
}

\author{
Mohamed Sayed Ali \\ Osman
}

\author{
Gamal Eldin Abd El_Hakim \\ M.
}

H. A. Khalifa

\begin{abstract}
Multi-Criteria Decision-Making (MCDM) is one of the most widely used decision methodologies in the sciences, business, and engineering worlds. MCDM refers to screening, prioritizing, ranking or selecting the alternatives based on human judgment from among a finite set of alternatives in terms of multiple usually conflicting criteria. In this paper, we develop a new methodology for solving multi- Criteria decision-making problems. The hybrid between three methods are used, these methods are: Simple Multi-Attribute Rating Technique (SMART), ELimination Et Choix Traduisant la Realité (ELECTRE) and The Technique for Order of Preference by Similarity to Ideal Solution (TOPSIS). The SMART method is applied to determinate the weights for each of the criteria to reflect its relative importance. Here, the ELECTRE method which based on the concept of an outranking relationship is used. Also, the TOPSIS method to rank all of the alternatives and to determine the best alternative is used. Finally, an illustrative numerical example is given to evaluate performance of the new developed methodology, where program system MATLAB is being used to obtain the results.
\end{abstract}

\section{Keywords}

MCDM; SMART; ELECTRE; TOPSIS

\section{INTRODUCTION}

Multi-Criteria Decision-Making (MCDM) is one of the most widely used scientific methodologies of decision support that intends to improve the quality of decisions by helping decision makers to make rational decisions that concordant with their preferences. Some of the most widely used MCDM methods are Analytic Hierarchical Process (AHP), Simple additive weighting (SAW), Simple Multi-Attribute Rating Technique (SMART), ELimination Et Choix Traduisant la Realité (Elimination and Choice Translating Reality) (ELECTRE) and The Technique for Order of Preference by Similarity to Ideal Solution (TOPSIS).

Generally speaking, a decision problem involves a set of alternatives described or evaluated by a set of criteria. Independence of further interpretation, a decision situation may be represented by a table of rows which corresponds to objects and columns to criteria, for each pair (criterion) there is a corresponding descriptor. We can also say that the table represents facts that know about the decision situation.

A typical MCDM problem is concerned with the task of ranking a finite number of decision alternatives, each of which is explicitly described in terms of different decision criteria which have to be taken into account simultaneously [Wang X. 2007] .

The main steps of MCDM are the following:

a) Establishing system evaluation criteria that relate system capabilities to goals;

b) List and describe alternatives for meeting objectives or goals (generating alternatives);

c) Evaluating alternatives in terms of criteria (the values of the criterion functions);

d) Selection of appropriate method to solve the problem.

e) Accepting one alternative as "optimal" (preferred).

f) If the final solution is not accepted, gather new information and go into the next iteration of multi-criteria optimization (Opricovic S., Tzeng Gwo-Hshiung 2004) .

Ehsan Pourjavad and Hadi Shirouyehzad, (2011) provided a comparison analysis of the three methods TOPSIS, ELECTRE and VIKOR are based on an aggregating function representing: eight parallel production lines from a factory will be analyzed using these three methods and also aggregate methods will be exploited in order to compare these methods.

Thor J. et al. (2013) reviewed and compared the application of four popular MCDM techniques in maintenance decision making. The methods included analytic hierarchy process (AHP), elimination and choice expressing reality (ELECTRE), Simple Additive Weighting (SAW), and technique for order preference by similarity to ideal solution (TOPSIS). The comparisons were based on the aspects of consistency, problem structure, concept, core process, and accuracy of final results.

1- Vice President of El Asher University, Cairo, Egypt.

2-3- Department of Operations Research, Institute of Statistical Studies \& Research, Cairo University, Cairo, Egypt.

Mohammed M. Alkhawlani (2015) developed three different decision support systems to address the JAC problem in the modern heterogeneous networks. These systems use SMART, TOPSIS, and VIKOR MCDM methods. Illustrative numerical examples for the developed systems are presented. The examples show 
that the choice of the MCDM tool can directly affect the ranking order of the available access networks, and hence, the selection of the MCDM methods is highly critical in any JAC solution.

\section{The formulation of MCDM problem}

In this paper, a MCDM problem with $m$ decision alternatives $A_{1}, A_{2}, \ldots, A_{m}$ and $n$ decision criteria $C_{1}, C_{2}$, $\ldots, C_{n}$ is considered. Assume that all alternatives score with respect to all criteria are known by the decision maker, $x_{i j}$ indicates the performance of alternative $A_{i}$ with respect to criterion $c_{j}$, (for $i=1,2, \ldots, m$, and $j=1,2, \ldots, n$ ) (Triantaphyllou E.,1998, Xiaoqian Sun ,2012).

The criteria may be grouped into two categories: benefit and cost. The benefit criteria are those criteria for maximization whose values are always the larger is the better. The cost criteria are those for minimization whose values are the smaller is the better. Then, a quantitative MCDM problem can be represented using decision matrix, as shown in Table 1

$$
\begin{aligned}
& C_{1} . C_{n}
\end{aligned}
$$

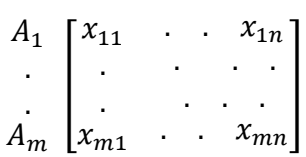

Table 1. The decision matrix

\section{A BRIEF OVERVIEW OF THREE MCDM METHODS}

\subsection{The Technique for Order of Preference by Similarity to Ideal} Solution METHOD

The Technique for Order of Preference by Similarity to Ideal Solution (TOPSIS), proposed by Hwang and Yoon (1981), is one of the most used methods to support MCDM. TOPSIS method is presented in Chen and Hwang (1992). The basic principle is that the chosen alternative should have the shortest distance from the ideal solution and the farthest distance from the negativeideal solution (Opricovic S. \& Tzeng Gwo-H. 2004).

The TOPSIS procedure consists of the following steps:

Step1: Calculate the normalized decision matrix.

To transform the various attribute dimensions into nondimensional attributes, which allows comparison across the attributes all the $x_{i j}$ values in the decision matrix $\left(x_{i j}\right)_{m x n}$ have to be normalized to form the matrix $R=$ $\left(r_{i j}\right)_{m x n}$. The normalized value $r_{i j}$ is calculated as: $r_{i j}=\frac{x_{i j}}{\sqrt{\sum_{i=1}^{m} x_{i j}^{2}}}, \quad j=1,2, \ldots, n$

Step 2: Calculate the weighted normalized decision matrix.

Calculate the weighted normalized decision matrix: by multiplying The normalized matrix by the weight $w_{j}$ of the $j^{\text {th }}$ criterion . The weighted normalized value $v_{i j}$ is calculated as

$$
\begin{array}{r}
v_{i j}=\quad w_{j} r_{i j} \quad i= \\
1,2, \ldots, m, j=1,2, \ldots, n, .
\end{array}
$$

Where, $w_{j}$ is the weight of the $j^{\text {th }}$ criterion, and $\sum_{j=1}^{n} w_{j}=1$

Step 3: Determine the ideal and negative-ideal solutions.

Ideal alternative: the one which has the best level for all criteria considered. Negative ideal alternative: the one which has the worst criterion values. The preferred alternative is the one having the shortest distance from an ideal solution $A^{*}$ and the farthest distance from a negative-ideal solution $A^{\prime} \quad$ Determine the ideal solution $A^{*}$ and negative-ideal solution $A^{\prime}$, the ideal solution $A^{*}=\left\{v_{1}^{*}, \ldots, v_{n}^{*}\right\}$, where, $v^{*}=\{$ $\max \left(v_{i j}\right)$ if $j \in J, \min \left(v_{i j}\right)$ if $\left.j \epsilon J^{\prime}\right\}$

negative-ideal solution $A^{\prime}=\left\{v_{1}^{\prime}, \ldots, v_{n}^{\prime}\right\}$, where $v^{\prime}=\{$ $\min \left(v_{i j}\right)$ if $\left.j \epsilon J, \max v_{i j}\right)$ if $\left.j \in J^{\prime}\right\}$

where $J$ is associated with benefit criteria (more is better), and $J^{\prime}$ is associated with cost criteria (less is better).

Step 4: Calculate the separation measures, using the $n$ dimensional Euclidean distance. The separation of each alternative from the ideal solution is given as:

$$
D_{i}^{*}=\left[\sum_{j=1}^{n}\left(v_{j}^{*}-v_{i j}\right)^{2}\right]^{1 / 2}, \quad i=1,2, \ldots, m
$$

Similarly, the separation from the negative ideal solution is given as:

$D_{i}^{\prime}=\left[\sum_{j=1}^{n}\left(v_{j}^{\prime}-v_{i j}\right)^{2}\right]^{1 / 2}, \quad i=1,2, \ldots, m$

Step 5: Calculate the relative closeness to the ideal solution. The relative closeness of the alternative $a_{i}$ with respect to $A^{*}$ is defined as following:

$$
\begin{aligned}
& C_{i}^{*}=D_{i}^{\prime} /\left(D_{i}^{*}+D_{i}^{\prime}\right), \quad 0<C_{i}^{*}<1, \quad i=1,2, \ldots, m \\
& \text { If } C_{i}^{*}=1 \text { then } a_{i}=A^{*} \text { and if } C_{i}^{*}=0 \text {, then } a_{i} \\
& =A^{\prime} . \text { Therefore, the conclusion is that } a_{i} \text { is closer to } \\
& A^{*} \text { if the } C_{i}^{*} \text { is closer to value } 1 .
\end{aligned}
$$

Step 6: Rank the preference order.

The best (optimal) alternative can now be decided according to the preference rank order of $C_{i}^{*}$, meaning that the bigger $C_{i}$ is the better the alternative. Therefore, the best alternative is the one that has the shortest distance to the ideal solution. The previous definition can also be used to demonstrate that any alternative which has the shortest distance from the ideal solution is also guaranteed to have the longest distance from the negative-ideal solution.

\subsection{Simple Multi-Attribute Rating Technique}

Simple Multi-Attribute Rating Technique (SMART) was originally described in 1977 by Edwards as the whole process of rating alternatives and weighting criteria. Methodology: The decision makers are asked to rank the importance of the changes in the criteria from the worst criteria levels to the best levels. Then 10 points are assigned to the least important criteria, and increasing number of points (without explicit upper limit) is assigned to the other criteria to address their importance relative to the least important criteria (Papadopoulos A. M. "Part I", Konidari P "Part II". 2011). The SMART Method procedure consists of the following steps: 
Step 1: Identify the decision-maker(s)

Step 2: Identify the alternatives

This step would identify the outcomes of possible actions, a data gathering process.

Step 3: Identify the criteria

It is important to limit the dimensions of value. This can be accomplished by restating and combining criteria, or by omitting less important criteria. It has been argued that it was not necessary to have a complete list of criteria. Fifteen were considered too many, and eight was considered sufficiently large.

Step 4: Assign values for each criteria

Ranking is a decision task that is easier than developing weights, for instance. This task is usually more difficult in group environments. However, groups including diverse opinions can result in a more thorough analysis of relative importance, as all sides of the issue are more likely to be voiced. An initial discussion could provide all group members with a common information base. This could be followed by identification of individual judgments of relative ranking.

Step 5: Determine the weight of each of the criteria The weights are elicited in two steps (see Edwards, 1977; von Winterfeldt and Edwards, 1986)

1. Rank the importance of the changes in the criteria from the worst criterion levels to the best levels.

2. Make ratio estimates of the relative importance of each criterion relative to the one ranked lowest in importance. Rank the importance of the changes in the criteria from the worst criterion levels to the best levels, begin with assigning 10 points to the least important criterion. The relative importance of the other criteria are then evaluated by giving them points from 10 upwards. The points given by the decision maker are normalized to get the weights (Poyhonen M.and Raimo P. Hamalainen 2001).

Step 6: Calculate a weighted average of the values assigned to each alternative:

This step allows normalization of the relative importance into weights summing to 1 .

$X_{i}=\sum W_{j} a_{i j}$

where, $W_{j}=$ normalized weight assigned for each evaluation criterion $C_{j}(j=1,2, \ldots, n)$ using smart, $\sum W_{j}=1$

$a_{i j}=$ scored performance of the alternative $A_{i}$ against criterion $C_{j}$.

Step 7: Rank the preference order.

A set of alternatives can now be preference ranked according to the descending order of $X_{i}$. An alternative with the higher score of $X_{i}$ is the better decision alternative.

\subsection{The ELECTRE Method}

The acronym ELECTRE stands for (Elimination et Choix Traduisant La Realité) ELimination and Choice Expressing the Reality, method was first introduced in 1966.
The ELECTRE methodology is based on the concordance and discordance indices to analyze the outranking relations among the alternatives.

An outranking relation is a binary relation which compares the arguments for and against a hypothesis Alternative $A$ is at least as good as Alternative $B$

The simplest method of the ELECTRE family is ELECTRE I.

The ELECTRE I generally includes three concepts, namely, the concordance index, discordance index, and the threshold value.

The ELECTRE I method is used to construct a partial ranking and choose a set of promising alternatives See Figueira et al (2004)( Janos Fulop, 2006). Steps of ELECTRE method (Pang J. ,et al.2011, MILANI A. S. et al., 2006, Mojahed M. et al. 2013) :

The ELECTRE Method procedure consists of the following steps:

Step 1: Calculate the normalized decision matrix.

For starting the method it's supposed that the problem has m alternatives $\quad\left(A_{1}, A_{2}, \ldots, A_{m},\right)$ and $n$ decision criteria $\left(C_{1}, C_{2}, \ldots, C_{n}\right)$. Each alternative is evaluated with respect to the $n$ criteria. All the values assigned to the alternatives with respect to each criterion form a decision matrix denoted by $X=\left(x_{i j}\right)_{m \times n}$

The decision matrix $X=\left(x_{i j}\right)_{m \times n} \quad$ is normalized by calculating $n_{i j}$ which represents the normalized criteria value.

$n_{i j}=\frac{x_{i j}}{\sqrt{\sum_{i=1}^{m} x_{i j}^{2}}} \quad, \quad i=1,2, \ldots, m, j=1,2, \ldots, n$

Step 2: Calculate the weighted normalized decision matrix.

The weighted normalized decision matrix $\quad V=$ $\left(v_{i j}\right)_{m \times n}$ is calculated.

$v_{i j}=n_{i j} \times w_{j}, i=1,2, \ldots, m, j=1,2, \ldots, n$

where

$w_{j}$ is the relative weight of the jth criterion by SMART method, where $\sum_{j=1}^{n} w_{j}=1$

Step 3: Determine the concordance and discordance set.

We divide the attribute sets into two different sets of concordance interval set $C(f, g)$ and discordance interval set $D(f, g)$.

The concordance set is determined. If alternative $A_{f}$ is preferred to alternative $A_{g}$ for all criteria, the concordance set is composed. This can be written as

$$
C(f, g)=\left\{j \mid V_{f j} \geq V_{g j}\right\} \quad f, g=
$$$$
1,2,3 \ldots, m, f \neq g
$$

In the formula $V_{f j}$ is the weighted normalized rating of alternative $A_{f}$ with respect to the $j^{\text {th }}$ criterion and $C(f, g)$ is the collection of criteria where $A_{f}$ is better than or equal to $A_{g}$. The discordance set is determined. It contains all criteria for which $A_{f}$ is worse than $A_{g}$. This can be written as, 
$$
D(f, g)=\left\{j \mid V_{f j}<V_{g j}\right\} \quad f, g=
$$ \\ $1,2,3 \ldots, m, f \neq g$ \\ On complementation of $C(f, g)$, we obtain the \\ discordance interval set $D(f, g)$ using (4):
}

Step 4: Calculate the concordance matrix.

The concordance index of $\mathrm{C}(\mathrm{f}, \mathrm{g})$ is defined as;

$$
\begin{aligned}
& C_{f g}=\sum_{j \in c(f, g)} \quad w_{j} \\
& , \sum_{j=1}^{n} w_{j}=1
\end{aligned}
$$

The concordance index is equal to the sum of the weights of the criteria that in The concordance set.

The concordance matrix can be formulated as follows:

$$
C=\left(\begin{array}{cccc}
- & C_{12} & \ldots & C_{1 m} \\
C_{21} & - & \ldots & C_{2 m} \\
\vdots & \vdots & \ddots & \vdots \\
C_{m 1} & C_{m 2} & \ldots & -
\end{array}\right)
$$

Step 5: Calculation of the discordance matrix

The discordance indexes are calculated. discordance index of $\mathrm{d}(\mathrm{f}, \mathrm{g})$ is defined as;

$$
d_{f g}=\frac{\max _{j \in D(f, g)}\left|V_{f j}-V_{g j}\right|}{\max _{j \in J}\left|V_{f j}-V_{g j}\right|}
$$

The discordance matrix can be formulated as follows:

$$
D=\left(\begin{array}{cccc}
- & d_{12} & \ldots & d_{1 m} \\
d_{21} & - & \ldots & d_{2 m} \\
\vdots & \vdots & \ddots & \vdots \\
d_{m 1} & d_{m 2} & \ldots & -
\end{array}\right)
$$

Step 6: Determine the concordance dominance matrix. compute threshold amount $(\bar{c})$ as follow:

$\bar{c}=\sum_{k=1}^{m} \sum_{l=1}^{m} c_{f, g} / m(m-1) \quad ;(m$ is dimension of matrix),
Thus, a Boolean matrix $(E)$ is given by:

$$
e_{f g}=1 \text { if } c_{f, g} \geq \bar{c}, \quad e_{f g}=0 \text { if } c_{f, g}<\bar{c}
$$

The above inequalities mean that if each element of matrix $\mathrm{C}$, is greater than or equal to, then " 1 " would be set in matrix $E$ (corresponding element).

Step 7: Determine the discordance dominance matrix.

So we calculate matrix of $K$.

compute threshold amount $(\bar{d})$ as follow:

$$
\bar{d}=\sum_{f=1}^{m} \sum_{g=1}^{m} d_{f g} / m(m-1),
$$
dimension of matrix),

the discordance index matrix $(K)$ is given by:

$k_{f g}=1$ if $d_{f, g} \leq \bar{d}, \quad k_{f g}=0$ if $d_{f, g}>\bar{d}$

Also the above inequalities mean that if each element of matrix $D$, is less than or equal to $\bar{d}$, then " 1 " would be set in matrix $K$ (corresponding element). For an outranking relation to be judged as true, both global indices should not violate their corresponding thresholds. That is, $C_{f g} \geq \bar{c}$, and $d_{f g}<\bar{d}$. Once the two tests are completed for all pairs of alternatives, the preferred alternatives are those that outrank more than being outranked.

Step 8: Determine the aggregate dominance matrix.

We also compute matrix $H$.

$h_{f, g}=e_{f, g} \cdot k_{f, g}$

So matrix $H$ is performed by multiplying corresponding elements of $E$ by $K$.

Step 9: Eliminate the less favorable alternative and rank them.

Finally, we must scan the columns of matrix $\mathrm{H}$, each column that has the least amount of number " 1 " should be chosen as the best one.

The Advantages and Disadvantages of these methods

\begin{tabular}{|c|l|l|}
\hline Method & Advantages & \multicolumn{1}{c|}{ Disadvantages } \\
\hline SMART & $\begin{array}{l}\text { Simple, allows for any type of weight } \\
\text { assignment technique. }\end{array}$ & $\begin{array}{l}\text { Procedure may not be convenient considering the } \\
\text { framework. }\end{array}$ \\
\hline ELECTRE & $\begin{array}{l}\text { Takes uncertainty and vagueness into } \\
\text { account. } \\
\text { Unlike many other MCDM methods. } \\
\text { comparison of the alternatives can be } \\
\text { achieved even if there is not a clear } \\
\text { preference. } \\
\text { Can use a large set of alternatives. }\end{array}$ & $\begin{array}{l}\text { Its process and outcome can be difficult to explain in } \\
\text { layman's terms; outranking causes the strengths and } \\
\text { weaknesses of the alternatives to not be directly } \\
\text { identified. } \\
\text { Because the roles played by the discordance and } \\
\text { concordance thresholds have no clear corollary in } \\
\text { common sense decision making it is difficult for a } \\
\text { decision maker to provide any justification for the } \\
\text { values chosen for these parameters. } \\
\text { requires a lot of primary data. }\end{array}$ \\
\hline TOPSIS & $\begin{array}{l}\text { Has a simple process; easy to use and } \\
\text { program. The number of steps remains } \\
\text { the same regardless of the number of } \\
\text { attributes. }\end{array}$ & $\begin{array}{l}\text { Its use of Euclidean Distance does not consider the } \\
\text { correlation of attributes. difficult to weight and keep } \\
\text { consistency of judgment. }\end{array}$ \\
\hline
\end{tabular}




\section{THE ALGORITHM OF THE HYBRID BETWEEN THREE METHODS AS FOLLOW}

Step 1: Determine the weight of each of the criteria by using SMART method

a. Rank the importance of the changes in the criteria from the worst criterion levels to the best levels.

b. Assign 10 points to the least important criterion.

c. The relative importance of the other criteria are then evaluated by giving them points from 10 upwards.

d. Normalized to get the weights, weights summing is 1.

e. Test of consistency until Consistency Rate reach to less than 0.1 .

finally we get the suitable weights of criteria $w_{j}$.

Step 2: Apply the ELECTRE method

a. Calculate the normalized decision matrix by $n_{i j}$ $=\frac{x_{i j}}{\sqrt{\sum_{i=1}^{m} x_{i j}^{2}}}$

b. Calculate the weighted normalized decision matrix $v_{i j}=n_{i j} \times w_{j}$

c. Determine the concordance and discordance set.

d. Calculate the concordance matrix and the discordance matrix

e. e- Determine the concordance dominance matrix and the discordance dominance matrix $C_{f g} \geq \bar{c}$, and $d_{f g}<\bar{d}$. f. Determine the aggregate dominance matrix.

g. Eliminate the less favorable alternative.

Step 3: Apply the TOPSIS method to rank the alternatives

a. Determine the ideal and negative-ideal solution.

b. Calculate the separation of each alternative from the ideal solution and from the negative ideal solution

c. Calculate the relative closeness to the ideal solution.

d. Rank the preference order.

\section{NUMERICAL EXAMPLE}

As shown in (Afshari A. et al.-2010), By using the set of seven criteria: $C_{1}, C_{2}, C_{3}, C_{4}, C_{5}, C_{6}, \square_{7}$ are all benefit criteria, together with the set of five alternatives $A_{1}, A_{2}, A_{3}, A_{4}, A_{5}$, first we apply the SMART method to determent the weights of criteria because the Disadvantages of both methods ( ELECTRE I and TOPSIS) require the assignment of a numerical weight and keep consistency of criteria , then we apply ELECTRE method to Eliminate the less favorable alternative, and after that we apply the TOPSIS method to rank the remainder alternatives because Advantage of this method is Simple and easy to understand, and the number of steps remains the same regardless of the number of criteria.

The comparison matrix is shown in Fig.1, indicating the relative importance of the criterion in the columns compared to the criterion in the rows.

\begin{tabular}{|l|llllllll|}
\hline & $C_{1}$ & $C_{2}$ & $C_{3}$ & $C_{4}$ & $C_{5}$ & $C_{6}$ & $C_{7}$ \\
\hline$C_{1}$ & 1 & 2 & 2 & 4 & 3 & 2 & 3 \\
\hline$C_{2}$ & 0.5 & 1 & 1 & 3 & 2 & 1 & 2 \\
\hline$C_{3}$ & 0.5 & 1 & 1 & 3 & 2 & 1 & 2 \\
\hline$C_{4}$ & 0.25 & 0.33 & 0.33 & 1 & 0.5 & 0.33 & 2 \\
\hline$C_{5}$ & 0.25 & 0.5 & 0.5 & 2 & 1 & 0.5 & 1 \\
\hline$C_{6}$ & 0.5 & 1 & 1 & 3 & 2 & 1 & 2 \\
\hline$C_{7}$ & 0.33 & 0.5 & 0.5 & 0.5 & 1 & 0.5 & 1 \\
\hline
\end{tabular}

Fig. 1: The comparison matrix of the criteria

\section{1- SMART method}

The steps of the SMART method mentioned earlier are applied here:

determine the weight of each of the criteria as follows:

Rank the importance of the changes in the criteria from the worst criterion levels to the best levels, $C_{7} \quad C_{4}$ $\begin{array}{lllll}C_{5} & C_{2} & C_{3} & C_{6} & C_{1} .\end{array}$ begins with assigning 10 points to the least important attribute. The relative importance of the other criteria are then evaluated by giving them points from 10 upwards.

$\begin{array}{cccccccc}C_{7} & C_{4} & C_{5} & C_{2} & C_{3} & C_{6} & C_{1} \\ 10 & 15 & 20 & 25 & 25 & 25 & 40\end{array}$

The points given by the decision maker are normalized to get the weights.

\begin{tabular}{|c|ccccccc|}
\hline Criteria & $C_{1}$ & $C_{2}$ & $C_{3}$ & $C_{4}$ & $C_{5}$ & $C_{6}$ & $C_{7}$ \\
\hline$W$ & 0.25 & 0.156 & 0.156 & 0.094 & 0.125 & 0.156 & 0.063 \\
\hline
\end{tabular}


Step 2: Calculate the weighted normalized decision matrix.

The weighted normalized decision matrix $\quad V=$ $\left(v_{i j}\right)_{5 \times 7}$ is calculated.

$$
v_{i j}=n_{i j} \times w_{j} \quad, i=1,2, \ldots, 5 \quad j=1,2, \ldots, 7
$$

where, $w_{j}$ is the relative weight of the jth criterion by SMART method

Table 2 : Weighted normalized decision matrix

\begin{tabular}{|r|ccccrrc|}
\hline & $C_{1}$ & $C_{2}$ & $C_{3}$ & $C_{4}$ & $C_{5}$ & $C_{6}$ & $C_{7}$ \\
\hline$A_{1}$ & 0.0971 & 0.1046 & 0.0493 & 0.0247 & 0.0281 & 0.0437 & 0.0114 \\
\hline$A_{2}$ & 0.0971 & 0.0598 & 0.0987 & 0.0494 & 0.0563 & 0.0655 & 0.0398 \\
\hline$A_{3}$ & 0.1700 & 0.0897 & 0.0658 & 0.0247 & 0.0703 & 0.1092 & 0.0170 \\
\hline$A_{4}$ & 0.0728 & 0.0299 & 0.0822 & 0.0370 & 0.0422 & 0.0437 & 0.0284 \\
\hline$A_{5}$ & 0.0971 & 0.0299 & 0.0329 & 0.0617 & 0.0703 & 0.0655 & 0.0341 \\
\hline
\end{tabular}

Step 3: Determine the concordance and discordance set.

The concordance set

$$
\begin{aligned}
& C(f, g)=\left\{j \mid V_{f j} \geq V_{g j}\right\}, \quad f, g=1,2,3,4,5, f \neq g \\
& C(1,2)=\{1,2\}, \ldots, C(5,4)=\{1,2,4,5,6,7\}
\end{aligned}
$$

The discordance set

$$
\begin{aligned}
& D(f, g)=\left\{j \mid V_{f j}<V_{g j}\right\} \quad f, g=1,2,3,4,5, f \neq g \\
& d(1,2)=\{3,4,5,6,7\}, \ldots, d(5,4)=\{3\}
\end{aligned}
$$

Step 4: Calculate the concordance matrix.

The concordance index of $\mathrm{C}(\mathrm{f}, \mathrm{g})$ is defined as;

$$
\begin{aligned}
& C_{f g}=\sum_{j \in c(f, g)} w_{j} \\
& C=\left(\begin{array}{ccccc}
- & 0.4060 & 0.2500 & 0.5620 & 0.5620 \\
0.8440 & - & 0.3130 & 1.0000 & 0.7810 \\
0.8440 & 0.6870 & - & 0.6870 & 0.8430 \\
0.5940 & 0 & 0.3130 & - & 0.3120 \\
0.6880 & 0.6250 & 0.2820 & 0.8440 & -
\end{array}\right)
\end{aligned}
$$

Step 5: Calculation of the discordance matrix

The discordance index of $d(f, g)$ is defined as,

$$
\begin{aligned}
& d_{f g}=\frac{\max _{j \in D(f, g)}\left|V_{f j}-V_{g j}\right|}{\max _{j \in J}\left|V_{f j}-V_{g j}\right|} \\
& \mathrm{d}=\left(\begin{array}{lllll}
- & 1 & 1 & 0.4402 & 0.5647 \\
0.9087 & - & 1 & 0 & 0.2138 \\
0.2051 & 0.4515 & - & 0.1693 & 0.5083 \\
1 & 1 & 1 & - & 0.5702 \\
1 & 1 & 1 & 1 & -
\end{array}\right)
\end{aligned}
$$

Step 6: Determine the concordance dominance matrix.

compute threshold amount $(\bar{c})$ as follow:

$\bar{c}=\sum_{k=1}^{m} \sum_{l=1}^{m} c_{f, g} / m(m-1)$

$\bar{c}=0.5719$

Thus, a Boolean matrix $(E)$ is given by:

$$
\begin{array}{cll}
e_{f g}=1 & \text { if } & c_{f, g} \geq \bar{c}, \\
e_{f g}=0 & \text { if } & c_{f, g}<\bar{c}
\end{array}
$$

$$
E=\left(\begin{array}{lllll}
0 & 0 & 0 & 0 & 0 \\
1 & 0 & 0 & 1 & 1 \\
1 & 1 & 0 & 1 & 1 \\
1 & 0 & 0 & 0 & 0 \\
1 & 1 & 0 & 1 & 0
\end{array}\right)
$$

Step 7: Determine the discordance dominance matrix.

So we calculate matrix of $K$.

compute threshold amount $(\bar{d})$ as follow:

$$
\bar{d}=\sum_{f=1}^{m} \sum_{g=1}^{m} d_{f g} / m(m-1)
$$

$\bar{d}=0.7016$

The discordance index matrix $(K)$ is given by:

$$
\begin{aligned}
k_{f g}=1 & \text { if } \\
d_{f, g}> & d_{f, g} \leq \bar{d}, \quad k_{f g}=0 \text { if } \\
K= & \left(\begin{array}{llllll}
1 & 0 & 0 & 1 & 1 \\
0 & 1 & 0 & 1 & 1 \\
1 & 1 & 1 & 1 & 1 \\
0 & 0 & 0 & 1 & 1 \\
0 & 0 & 0 & 0 & 1
\end{array}\right)
\end{aligned}
$$

Step 8: Determine the aggregate dominance matrix.

We also compute matrix $H . \quad h_{f, g}=e_{f, g} \cdot k_{f, g}$

$$
H=\left(\begin{array}{lllll}
0 & 0 & 0 & 0 & 0 \\
0 & 0 & 0 & 1 & 1 \\
1 & 1 & 0 & 1 & 1 \\
0 & 0 & 0 & 0 & 0 \\
0 & 0 & 0 & 0 & 0
\end{array}\right)
$$

Step 9: Eliminate the less favorable alternative

Finally, we must scan the columns of matrix $H$, each column that has the least amount of number "1" should be chosen as the best one.

$A_{3}$ is the best alternative, and $A_{1}$ and $A_{2}$ are equally and $A_{4}$ and $A_{5}$ are the worst alternatives and are equally ,. for that we can't rank them, $A_{3}>A_{1}=A_{2}$ (in equal value) $>A_{4}=A_{5}$ (in equal value).

Then we rank them by TOPSIS method.

Third, we apply the TOPSIS method to rank them 
(a) Determine the ideal and negative-ideal solution

The preferred alternative is the one having the shortest distance from an ideal solution $A^{*}$ and the farthest distance from a negative-ideal solution $A^{\prime}$. Determine the ideal solution $A^{*}$ and negative-ideal solution $A^{\prime}$ as shown in Table 3 .

Table 3: Ideal solutions $\boldsymbol{A}^{*}$ and negative-ideal solutions $\boldsymbol{A}^{\prime}$

\begin{tabular}{|c|ccccccc|}
\hline & $C_{1}$ & $C_{2}$ & $C_{3}$ & $C_{4}$ & $C_{5}$ & $C_{6}$ & $C_{7}$ \\
\hline$A^{*}$ & 0.1700 & 0.1046 & 0.0987 & 0.0617 & 0.0703 & 0.1092 & 0.0398 \\
\hline$A^{\prime}$ & 0.0728 & 0.0299 & 0.0329 & 0.0247 & 0.0281 & 0.0437 & 0.0114 \\
\hline
\end{tabular}

(b) Calculate the separation measures, calculate the Euclidean distances $D_{i}^{*}$ and $D_{i}^{\prime}$ of alternative $A_{i}$ from the ideal and negative-ideal solutions $A^{*}$ and $A^{\prime}$, respectively $\quad D_{i}^{*}=\left[\sum_{j=1}^{7}\left(v_{j}^{*}-v_{i j}\right)^{2}\right]^{1 / 2}$; $i=1,2, \ldots, 5$,

$i=1,2, \ldots, 5$,

$$
D_{i}^{\prime}=\left[\sum_{j=1}^{7}\left(v_{j}^{\prime}-v_{i j}\right)^{2}\right]^{1 / 2},
$$

$D^{*}=\left[\begin{array}{lllll}0.1265 & 0.0979 & 0.0565 & 0.1453 & 0.1310\end{array}\right]$
$D_{i}^{\prime}=\left[\begin{array}{lllll}0.0803 & 0.0922 & 0.1421 & 0.0554 & 0.0688\end{array}\right]$

(c) Calculate the relative closeness to the ideal solution $C_{i}^{*}$

$$
\begin{aligned}
& <1 \quad i=1,2, \ldots, 5 \text {. } \\
& C_{i}^{*}=\left[\begin{array}{ccccc}
A_{1} & A_{2} & A_{3} & A_{4} & A_{5} \\
0.3883 & 0.4850 & 0.7155 & 0.2762
\end{array}\right. \\
& 0.3444 \text { ] }
\end{aligned}
$$

The best alternative is $A_{3}$ and then $A_{2}, A_{1}, A_{5}$ and $A_{4}$.

Table 4: The final results of the methods

\begin{tabular}{|l|l|}
\hline \multicolumn{1}{|c|}{ Method } & \multicolumn{1}{c|}{ Final results } \\
\hline SMART & $A_{3}>A_{2}>A_{5}>A_{1}>A_{4}$. \\
\hline TOPSIS & $A_{3}>A_{2}>A_{1}>A_{5}>A_{4}$. \\
\hline ELECTRE & $A_{3}>A_{1}=A_{2}>A_{4}=A_{5}$ \\
\hline Hybrid between them & $A_{3}>A_{2}>A_{1}>A_{5}>A_{4}$. \\
\hline
\end{tabular}

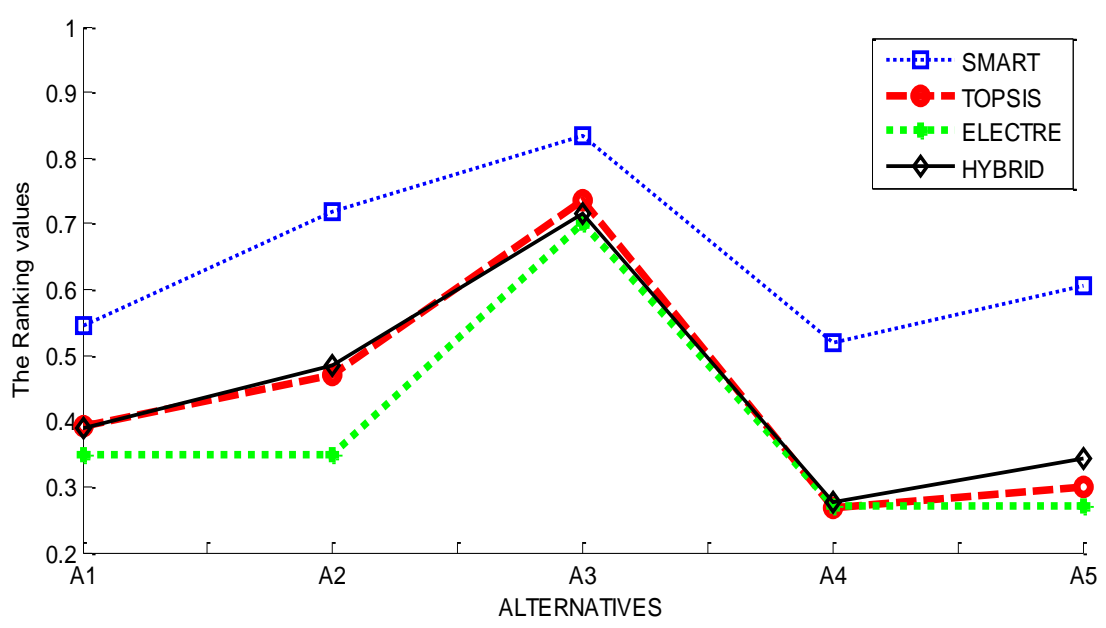

Fig 2: plotting of the rank of Alternatives

\section{CONCLUSIONS}

Generally speaking, the number of selected alternatives strongly depends on the threshold values $\bar{c}$ and $\bar{d}$ in ELECTRE method.

In this study, we have provided a new methodology for solving multi-attribute decision-making problems. The new approach integrate the concept of 'outranking relationship' of ELECTRE method. We Can be selected suitable alternative and rank all of the alternatives by using hybrid between SMART, ELECTRE I and TOPSIS methods. Firstly, we adopt SMART method to calculate the suitable weights of criteria. Then, ELECTRE method to Eliminate the less favorable alternative, the final result $A_{3}$ is the best alternative, $A_{1}$ and $A_{2}$ are equally and $A_{4}$ and $A_{5}$ are the worst alternatives and are equally, and finally we also used the TOPSIS to rank all of the alternatives and to determine the best alternative. We also illustrated numerical example to demonstrate its practicality and effectiveness. we apply the SMART, ELECTRE and TOPSIS method separately to the 
Example , and then apply the hybrid to the same Ex. the results are illustrated in Table 4 and Fig 2.

In general ELECTRE method used in large set of alternatives.

\section{REFERENCES}

[1] Afshari A., Mojahed M. and Yusuff R. M., "Simple Additive Weighting approach to Personnel Selection problem", International Journal of Innovation, Management and Technology, Vol. 1, No. 5, (2010).

[2] Ehsan Pourjavad and Hadi Shirouyehzad ," A MCDM Approach for Prioritizing Production Lines: A Case Study", International Journal of Business and Management, Vol. 6, No. 10, (2011), p221 229.

[3] Janos Fulop," Introduction to Decision Making Methods ", Laboratory of Operations Research and Decision Systems, Computer and Automation Institute, Hungarian Academy of Sciences (2006).

[4] MILANI A. S., SHANIAN A., AND EL-LAHHAM C., "Using Different Electre Methods In Strategic Planning In The Presence Of Human Behavioral Resistance", Volume 2006, Article ID 10936,(2006) , Pages 1-19.

[5] Mohammed M. Alkhawlani ,"Application of SMART, TOPSIS, and VIKOR Systems in Joint Admission Control", Volume-4 Issue-3, (2015).

[6] Mojahed M. , Marjani M. E. , Afshari A. , Marjani S. ,"USING ELECTRE-AHP AS A MIXED METHOD FOR PERSONNEL SELECTION", (2013)

[7] Opricovic S., Tzeng Gwo-H. ," Compromise solution by MCDM methods: A comparative analysis of VIKOR and TOPSIS",European Journal of Operational Research 156 , (2004), pp 445-455.

[8] Pang J., Zhang G. and Chen G. "ELECTRE I Decision Model Of Reliability Design Scheme For Computer Numerical Control Machine", VOL. 6, NO. 5, (2011).

[9] Papadopoulos A. M. (Part I), Konidari P. (Part II)," Overvie and selection of multi- criteria evaluation methods for mitigation/ adaptation policy nstruments", Greece, (2011).

[10] Poyhonen M., Raimo P. Hamalainen,"On the convergence of multiattribute weighting methods,(2001), pp.569-585.

[11] Thor J. , Siew-Hong Ding , Kamaruddin S. " Comparison of Multi Criteria Decision Making Methods From The Maintenance Alternative Selection Perspective ", The International Journal Of Engineering And Science (IJES) Volume 2 (2013), pp 27-34.

[12] Triantaphyllou E., Shu B., Sanchez S. Nieto, and Ray T.," Multi-Criteria Decision Making: An Operations Research Approach", Vol. 15, (1998), pp. 175-186.

[13] Wang X. "Study Of Ranking Irregularities When Evaluating Alternatives By Using Some Electre Methods And A Proposed New MCDM Method Based On Regret And Rejoicing", A Thesis Master of Science in Industrial Engineering (2007).

[14] Xiaoqian Sun," Multiple Criteria Decision Analysis Techniques in Aircraft Design and Evaluation Processes", PhD, (2012). 